\title{
Learning through computers: Uncovering students' thought processes while solving physics problems
}

\author{
Benson Soong \\ University of Cambridge
}

\begin{abstract}
This paper presents a study that illustrates how the author and an in service secondary school teacher used basic synchronous computer mediated communications (CMC) technology to help them uncover students' physics preconceptions and thought processes (including their misconceptions and misunderstandings) in a real class setting. In this paper, I first provide a discussion on constructivist science learning environments, highlighting the central role students' preconceptions play in their learning in the science subject domain. Next, I argue that in light of constructivist learning principles, learning may be viewed as a conceptual change process; a process which is facilitated by active problem solving attempts. I then present a study (which was part of a larger design experiment) whereby student pairs worked collaboratively to solve physics questions via NetMeeting, a free CMC software from Microsoft. Results pertaining to how protocol data of students' problem solving attempts (as recorded by NetMeeting) provided us with rich insights into the students' thought processes that are normally not easily accessible are discussed. Finally, I consider further research work that could be done in light of the findings of this study.
\end{abstract}

\section{Constructivist science learning environments and the centrality of students' prior knowledge}

Over the last two decades, there has been growing acknowledgement of the need for creating and assessing new models of teaching introductory physics (e.g. Arons, 1989; Merzbacher, 1990; Schwartz, 1990; Heller \& Heller, 1999; Ogborn, 2004; Cahyadi, 2007). Due at least in part to educators' paradigm shift towards constructivist learning principles, it is increasingly being recognised that a student's mind is not a tabula rasa; students come to classrooms with prior knowledge and preconceptions, and they interpret what their teachers are saying based on these preconceptions. As Ogborn (2004) explained in his review of physics education,

Perhaps the strongest result to emerge from this research [in physics education] has been the fundamental importance of the ideas students hold about the physical world, in deciding how they understand what they are taught. The point is ultimately simple and obvious: everybody understands what they are told as a kind of 'best fit' to what they already know. (p.85)

Against such a backdrop, it has been recognised that students' preconceptions (or misconceptions) can often impede their learning and understanding of normative science concepts (e.g. McDermott et al., 1987; Goldberg \& Anderson, 1989; Trowbridge \& McDermott, 1980; Trowbridge \& McDermott, 1981; Aguirre, 1988; Bowden et al., 1992; Voska \& Heikkinen, 2000). Indeed, Kang et al. (2005) noted that "many science educators ... have an interest in students' pre-instructional or alternative conceptions 
because knowing them is an essential starting point to develop strategies and/or processes for introducing new scientific concepts," adding that, "[t]he research on students' alternative conceptions in various content domains rapidly expanded during the 1980 s ... and remains an important agenda to be investigated" (p.1038). An instance of how students' preconceptions impede their learning is provided by Ogborn (2004), who suggested that perhaps due to students' intuitive understanding and experience with moving and non-moving objects, they "regularly refuse to believe the First Law [of Motion], and import into mechanics ideas of their own about a 'force' needed to keep objects in motion" (p.85).

Unlike domains such as Civics or Moral education where the issues involved may be based largely on societal opinions which may vary from country to country or community to community, physics concepts and principles are conceptually clear, with universally accepted and established normative views on the phenomena addressed by physics (e.g. Newton's Laws of Motion), which students are required to learn. The recognition of students' preconceptions vis-à-vis normative scientific views has led to an increased focus on uncovering, understanding, and dealing with students' preconceptions and misconceptions. For example, the Department of Physics at Montana State University (Montana, 2008) maintains a website of common students' physics misconceptions, while the Comprehensive Conceptual Curriculum for Physics (C3P) project at the University of Dallas (Dallas, 2008) provides training workshops for teachers, which covers common preconceptions and misconceptions that many American high school physics teachers and college professors have recognised in their students. This focus and importance of addressing students' preconceptions and misconceptions in science learning environments is epitomised by Olenick (2005), who remarked that,

Our goal is for students' preconceptions to be lost in time and our stakes are high. Without the next generation of scientists and a citizenry that can make intelligent and informed decisions about science, our future will be lost. (p. 16; emphasis added)

An example of a science learning environment that explicitly takes into account students' prior knowledge and preconceptions is the Instructional Design Model of The University of Minnesota (for a full review, see Heller \& Heller, 1999). The University's Instructional Design Model is currently still being used by the University's physics department as a framework for teaching large introductory courses, and this model has been credited with producing students who are successful physics learners. To illustrate the model's success, Heller and Heller (1999) reported that after several years of data collection, which included evaluations of students' problem solving skills and conceptual understanding of physics, interviews with students, and anonymous evaluations by students and teaching assistants, the results of investigations of student learning in this environment show that the University of Minnesota's physics learning environment is "effective in teaching both concepts and problem-solving skills. It is also appreciated by the students" (Heller \& Heller, 1999, p.12).

The Instructional Design Model posits that most students enter the course with poor learning and problem solving strategies, and with many misconceptions about basic physics phenomena. Hence, the "goal of any instructional design is the transformation of students from an initial state to a final state of improved intellectual performance" (Heller \& Heller, 1999, p.1). The importance of uncovering students' initial states (including their prior knowledge and preconceptions; see Figure 1) is unmistakable in the University of Minnesota Instructional Design Model for learning physics. 


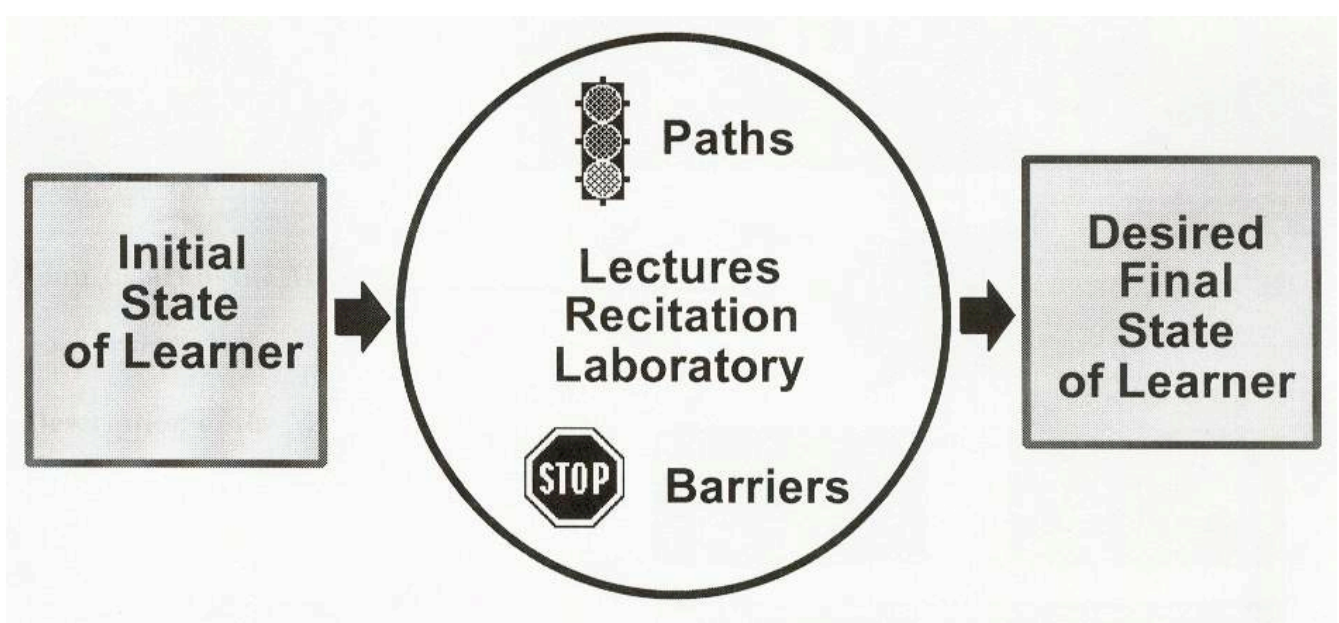

Transformation Process

Figure 1: The University of Minnesota Instructional Design Model

(Heller \& Heller, 1999, p.1)

\title{
Learning as conceptual change
}

The centrality of addressing students' prior knowledge in science learning environments is concomitant with a key tenet of constructivism, where learning is said to be knowledge dependent because people make use of current knowledge to construct new knowledge (Resnick, 1989; the other key tenet is the active intellectual involvements of students; see Mortimer \& Scott, 2003). However, the implications of prior knowledge force a theoretical shift to viewing learning as conceptual change (Strike \& Posner, 1985; Roschelle, 1995). This view is articulated by Nersessian (1998), who explained,

\begin{abstract}
[C]onsiderable research has established that students are not blank slates on which teachers can imprint scientific knowledge. Students come to school with intuitive conceptualizations of physical phenomena in several domains which differ from those of science. Further, these intuitive conceptualizations prove to be highly resistant to instruction. Developing pedagogical strategies to facilitate the shift from intuitive to scientific understanding requires insight into the nature and processes of conceptual change. (p.158; emphasis added)
\end{abstract}

It is important to recognise that viewing learning as conceptual change provides only a partial view of learning. There are other forms of learning that may not be seen as conceptual change. One such example is the learning of new psychomotor skills (e.g. carpentry, cycling). However, in learning about subject domains that involve many principles and concepts (e.g. science domains), learning can be viewed as conceptual change. To explain further, take for example the physical phenomenon of free fall. Many students have a preconceived notion that objects with greater mass fall faster than objects with lesser mass. Because of the students' misconceptions, teaching these students about falling objects and their associated rate of acceleration under free fall involves "correcting" misconceptions, such as greater mass implies a higher acceleration under free fall. In this light, students who have undergone a conceptual change, from misconception(s) to normative view(s), may be viewed as having 
improved their understanding, which is a reason why Heller and Heller (1999) referred to the learning of physics as a transformation process.

Given the theoretical shift to viewing learning as conceptual change, how is the process of conceptual change (and hence learning) facilitated in students? Nersessian (1998) posits that "conceptual innovation and change occurs in a problem solving process" (p.162; emphasis added). As Rorty (1991) explains, knowledge is gained through the construction process rather than in the finding; it is not the content stored in memory, but rather the activity of constructing it (c.f. Salomon, 1998). While this "construction process" is not restricted only to problem solving, problem solving - as a learning process - is effective because it encourages students to be actively involved in the process while allowing them to learn the application of concepts in an appropriate context. This connection between problem solving and learning has been established by other researchers, such as Shuell (1990) who concludes that "[o]f the different metaphors used to characterize classroom teaching and learning, a 'problem solving' metaphor is most consistent with current conceptions of meaningful learning" (p. 102; see also Shuell, 1986).

\section{Capturing students' prior knowledge and thought processes}

In view of the centrality for teachers to uncover students' preconceptions in constructivist science learning environments, and in accordance with the belief that conceptual change (and hence learning) may be facilitated in a problem solving environment, how can regular secondary school science teachers, who do not have access to teaching assistants or expensive technology, capture students' preconceptions and thought processes in a relatively economical manner? I posit that in order to capture students' thought processes (and preconceptions), these thought processes must first be articulated in a manner that is suitable for capturing. I propose that student discourse is one such appropriate manner. After all, from a sociocultural perspective, "the human mind is mediated" (Lantolf, 2000, p.1; emphasis in original) predominately by a process Mercer (1995) describes as "the guided construction of knowledge", which is "a communication process ... in which one person helps another to develop their knowledge and understanding" (p. 1). Other prior research has also drawn attention to the importance of student discourse in the learning process. For example, Duffy and Cunningham (1996) define learning as a "social, communicative, and discursive process" which is "inexorably grounded in talk" (p.181). There are two broad levels of potential benefits which discourse in class could bring to the students, namely individual level benefits (intra-personal benefits) and social level benefits (inter-personal benefits).

At the individual level, meaningful discussions in classrooms can lead to deep learning, as it facilitates the generation of contextual knowledge and scientific conceptual understanding (Hsi, 1997), and promotes reasoning in students (Piaget, 1972). By providing an opportunity for students to be exposed to the views and beliefs of others, it may motivate the revision of ideas and misconceptions (Strike \& Posner, 1985). In addition, "[d]ialogue and discourse encourages the higher order thinking skills of cognitive conflict and resolution in providing context and a mechanism for explanation, justification and reason" (Lockyer et al., 1999, p.56).

At the wider social level, it is the learners' interactions with instructors and other learners that "give them perspective, place them within a community of learning, and 
contribute to their mastery of concepts and skills" (Price \& Petre, 1997, p. 1041). Such social interactions are vital in nurturing the spirit of learning, since "the individual ... becomes familiar with its methods and subject matters, acquires needed skill, and is saturated with its emotional spirit" (Dewey, 1916, p. 26). The concepts and skills exposed at the social level would then later be internalised (Vygotsky, 1978), leading to individual improvements.

Given that meaningful student discourse provides a particularly rich ground for uncovering students' preconceptions or misconceptions and thought processes, how can secondary science teachers capture such discourse in an economical fashion? I posit that unique affordances offered by computer mediated communication (CMC) could provide us with an economical solution, and designed a learning intervention that made use of basic CMC technology for this purpose. As a research community, we are already familiar with the generic advantages of using computers as a medium through which learning can occur. However, the uniqueness of the permanency of the electronic medium is an area often overlooked by researchers and designers of learning environment. I believe the permanency property offered by the electronic medium can provide teachers with a powerful tool to better understand students' thinking, thereby better facilitating student learning.

An example of work in this area is provided by Hung's (1996) demonstration of the phenomenon of epistemological transformation through peer apprenticeship. Hung placed two students who were quite different in character in a distributed environment in an out of school context. There, the students worked on solving mathematical problems exclusively in a synchronous CMC environment. Hung explains that "each student constructs knowledge through a shared whiteboard and a chatbox facility" (1996, p.16). The chatbox facility allowed the two students to converse via typed text, while the shared whiteboard allowed for pictorial drawings and ideas to be depicted and discussed. From the analysis of the protocol data obtained from the collaborative problem solving efforts of the students, Hung conceptualised the peer apprenticeship learning model. Peer apprenticeship learning (Hung, 1996; Hung, 1998) denotes the process whereby an individual's personal beliefs, disposition, and epistemology are transformed through an "apprenticeship like" learning process (Hung, 1998).

In another CMC study involving physics collaborative problem solving, Soong \& Chee (2000) demonstrated how the discussion logs (which were saved and printed out for analysis) of physics student dyads participating in synchronous computer mediated, problem solving provided them with sufficiently rich data about the students' thought processes, thereby enabling rich insights into how the students were thinking, and exposing their misconceptions of various science concepts in the process.

There are two important observations that we can draw from the two studies described above. Firstly, a computer mediated medium is sufficiently rich to allow for meaningful knowledge co-construction and negotiation between students. Hence, well-designed CMC environments should not impede learning. Secondly, the studies show that getting students to work collaboratively on solving problems in a synchronous CMC environment could provide a rich field for gleaning students' conceptions in a "naturally occurring" context. More specifically, because cognitive and metacognitive activities are normally hidden and private, the use of computer mediated collaborative tools can "force" the students to put more effort into making 
explicit their thought processes, since body language and other forms of intangible communication means are no longer viable. This would make students' cognitive and metacognitive activities overt and subject to our analysis (Hung, 1998), thereby allowing us to obtain deeper insights into students' current knowledge and understanding.

\section{The study}

While both Hung's (1996) and Soong and Chee's (2000) research work revealed that analysing computer generated logs from students' collaborative problem solving efforts can provide deep insights into students' thought processes and preconceptions (along with students' misconceptions and misunderstandings; see also Lund \& Baker, 1999), their research studies were not conducted in real world classrooms involving in service teachers. Indeed, Chen and Looi (2007) lamented that there is little practice reported on research conducted into online discussions in real world classroom settings, which led $\mathrm{Ng} \&$ Cheung (2007) to suggest that there is a need for further research concerned with in class online discussion. Hence, it appears timely for me to report on an unpublished study I conducted several years ago, which is now my current research focus. In that study, I implemented a computer mediated, discoursecentric, collaborative problem solving environment, in a real world classroom of 37 students. In this paper, I discuss only the computer mediated activities, and provide evidence only pertaining to how basic synchronous CMC technology was used by us (the author and the teacher) to help uncover students' physics thought processes and preconceptions (along with their misconceptions and misunderstandings).

My learning intervention was implemented in an academically average public secondary school in Singapore during term time. The school principal had given me permission to conduct this research study at the school premises if I could successfully seek out a volunteer teacher and class. One physics teacher (and his secondary 4 physics class of 37 students aged 15 to 16; 13 boys and 24 girls) volunteered to participate in the study. I had worked with four of this teacher's students in one of my prior studies. Hence, the teacher was quite familiar with my research work. He said that one reason for participating in the study was to discover what was going on "in the students' heads" when they were solving questions. Given these reasons, I was very comfortable with having him as a teacher in the learning environment. The first thing I did to prepare him was to show him some protocol data of students' collaborative problem solving efforts. As he read through the log, he spotted the same misconceptions as I did. Hence, I was assured that he understood the basic techniques and objectives associated with analysing the students' problem solving logs (which is not difficult). The teacher had two years of experience as a physics teacher in that school, and was previously working in an IT related position. Hence, he had no difficulty understanding the set up and operation of the computers for the computer mediated sessions, and needed no assistance in this area. We (the collective term used to describe the teacher and the author) also ascertained that the students were comfortable working in a computer based environment.

In addition to the use of the classroom that the students occupy during their regular lessons, we requested the use of 37 computers and were given the use of two computer labs (every public secondary school in Singapore has at least two computer labs, containing about 40 computers). One of the computer labs housed 21 computers, while the other lab housed 16 computers. All computers in both labs were DELL Pentium 200 
PCs that ran Microsoft Windows 95 as the operating system. These PCs were also preinstalled with Microsoft NetMeeting (a fee-free CMC software bundled with Microsoft 95/98/ME/XP). They were networked together via the school's intranet, and the students had access to a large shared directory. We used NetMeeting as the computer mediated tool for collaborative problem solving because it features a shared whiteboard space and chat facility, has a user friendly interface, and supports PPP (Point to Point Protocol), a TCP/IP-based protocol that does not require a server. In addition, prior studies (e.g. Soong \& Chee, 2000) have shown that NetMeeting is sufficiently rich to allow for meaningful knowledge negotiation between students and supportive of obtaining students' current knowledge and understanding in a "naturally occurring" manner.

The students were immersed in the learning intervention for nine weeks during their academic term of year 2000. The weekly timetable that we adhered to is shown in Table 1.

Table 1: Weekly physics lesson timetable

\begin{tabular}{|c|c|}
\hline Day of week & Time available (continuous periods in class) \\
\hline Tuesday & 1.5 hours \\
\hline Wednesday & 0.5 hours \\
\hline Friday & 1 hour \\
\hline
\end{tabular}

Given this timetable, we designated Tuesdays as "collaborative problem solving" day, and Fridays as "instruction day." Because the lessons on Wednesday were very short, we used Wednesday as a "fall over day," where students completed any questions that they failed to complete on Tuesday. Our plan was straightforward - results and outcomes of Tuesday's collaborative problem solving session would decide what the students did on Wednesday, and what the teacher "taught" on Friday.

During the study, we conducted a total of four computer mediated, collaborative problem solving sessions (on Tuesdays) with the topics summarised in Table 2.

Table 2: Schedule of sessions conducted and topics covered on Tuesdays

\begin{tabular}{|c|l|}
\hline Week no. & \multicolumn{1}{c|}{ Topic covered } \\
\hline 1 & Speed, velocity, acceleration \\
\hline 2 & $\begin{array}{l}\text { Forces } \\
\text { Mass, weight and centre of mass } \\
\text { Scalars and vectors }\end{array}$ \\
\hline 7 & $\begin{array}{l}\text { General wave properties } \\
\text { Light } \\
\text { Sound }\end{array}$ \\
\hline 8 & $\begin{array}{l}\text { Simple phenomena of magnetism } \\
\text { Electricity }\end{array}$ \\
\hline
\end{tabular}

For the computer mediated, collaborative problem solving sessions, twenty-one students were assigned to Lab 1, while the remaining students were assigned to Lab 2. A five minute walk separated the two labs, and for all the NetMeeting collaborative problem solving session conducted, the teacher took charge of Lab 2, while the author oversaw Lab 1. With respect to the formation of computer mediated, collaborative problem solving teams, prior studies (e.g. Hung, 1996; Soong \& Chee, 2000) revealed 
that grouping two students to form a problem solving team was optimal. Our personal experience had been that the more students we grouped together into a team, the more frequent was the "free loader" phenomenon. However, as there was an odd number of students, one group had a size of three students.

The NetMeeting environment consisted of a chatbox and a whiteboard facility. The chatbox allowed two students to converse via typed text, while the shared whiteboard allowed pictorial drawings and ideas to be depicted and discussed. Figure 2 shows a snapshot of NetMeeting's chatbox and whiteboard screens. Students were required to regularly "save" both the shared chatbox and the whiteboard on a removable medium, which was submitted to the teacher or author at the end of the session for printing and analysis.

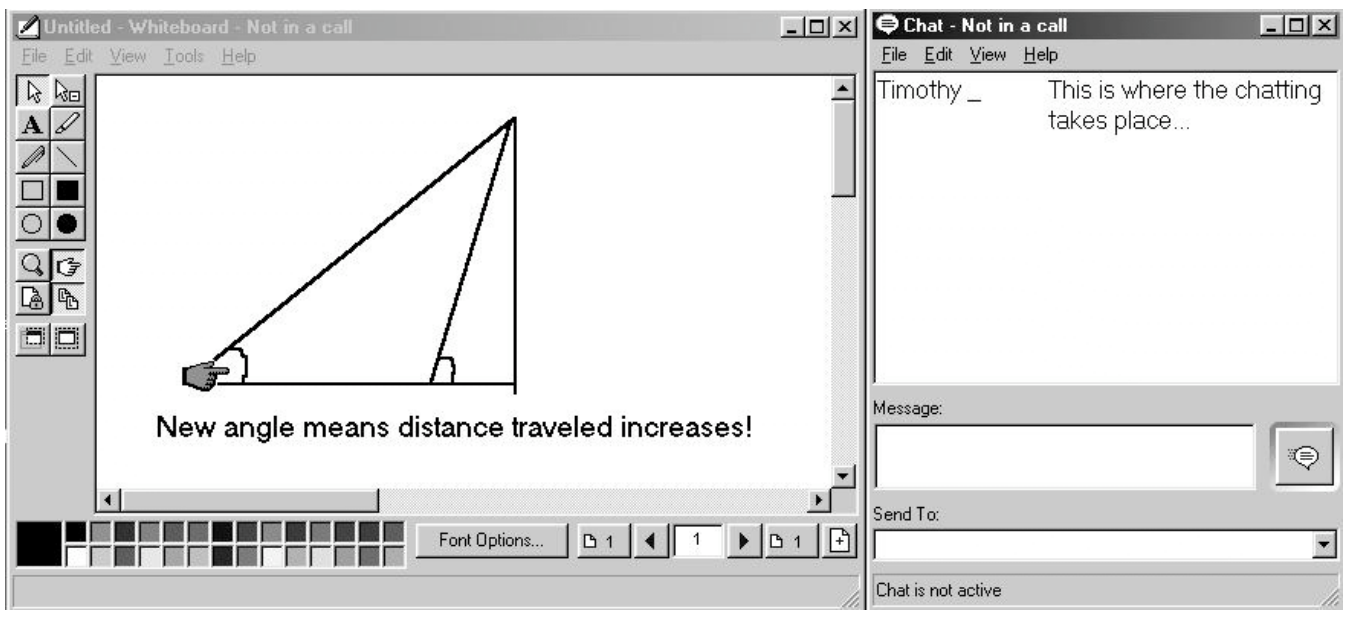

Figure 2: The CMC environment

Just prior to every computer mediated problem solving session, we turned on all the computers and started up NetMeeting. We then assigned random nicknames to each computer and connected two computers together by means of NetMeeting's "call" feature. We used random nicknames because we did not want students to know the identity of their problem solving partner. This approach was intended to "reduce differences in social status and prestige, thereby providing a more egalitarian context for social interaction. This may lead to more open and spontaneous participation" (Jehng, 1999, p.675). The students were informed of the lab and computer they were assigned to an hour before the session began and were not provided with any partnering information. When the students first got to the computers, they accessed a special folder in the shared directory (with read only permission) in order to access the questions posed for that particular session. They then proceeded to collaboratively solve the given problem with their assigned partner(s).

Figure 3 shows the Lab 1 layout and partnering plan that was used in one of our computer mediated, collaborative problem solving sessions. The arrows depict the directions the students were facing, while each box represents a computer. The arrow contains the nickname assigned to the student, and the box contains the partnering information and that computer's IP address. For example, Figure 3 includes a student with the nickname "Eda" using the computer that has an IP address of 10.148.29.6. "Eda" has been assigned to group 8, which included student "Kisko". The principle 
behind the allocation of sitting and partnering arrangements was that we wanted it to be harder for students to discover who their partners were by simply turning their heads. In the layout design shown in Figure 3, all the computers have been allocated in accordance with this principle, except for the computers with IP addresses 10.148.28.246 and 10.148.29.12 that were directly behind each other. Hence, the students assigned to these two computers were assigned partners in the other lab. We did not assign all partners to different labs because doing so would greatly lengthen the time required to set up the computers and network connections; other classes would not be able to use the computers during those times as well.

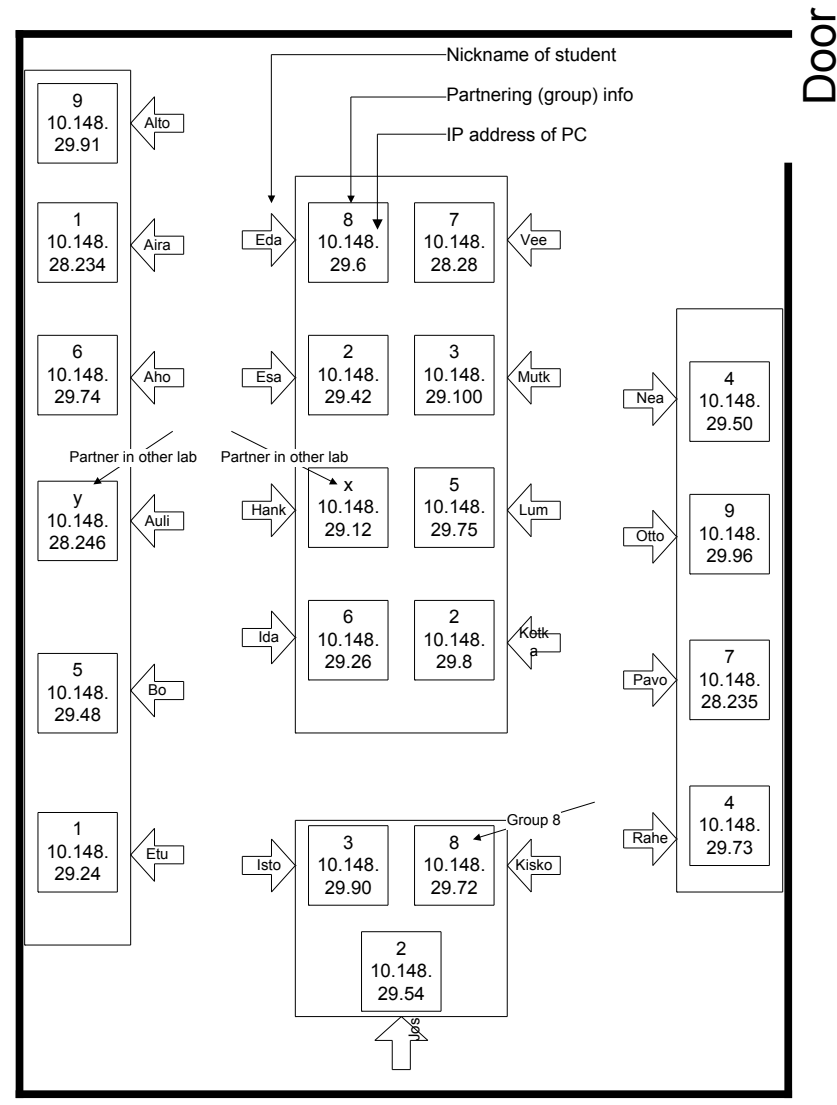

Figure 3: Lab 1 layout and partnering information

Prior to the first CMC session, students were provided with a set of ground rules for how they should behave during the computer mediated, collaborative problem solving session. The ground rules were:

- Write in standard English;

- Be nice to your partner;

- Do not reveal your identity;

- Express your ideas and workings clearly and neatly;

- Express all your opinions and doubts, and discuss them with your partner;

- Be focused. Do not do anything else other than problem solving with your paper (e.g. no web browsing); 
- Your answers must be backed by reasons;

- Only call for the teacher after both your partner and you agree on the answer and the workings.

\section{Results}

To illustrate how basic synchronous CMC technology (in this case, NetMeeting) may be used by teachers to help uncover students' physics preconceptions and thought processes (including their misconceptions and misunderstandings), we provide protocol data taken verbatim from students' chat logs. Due to space constraints, we shall provide snippets of chat logs between selected student pairs for the first CMC session, and for one specific misconception identified. These protocol data demonstrates that many students generally have the same misconceptions, albeit to a different extent.

CMC Session 1: Speed, velocity, acceleration

The first problem posed during CMC session 1 was the falling brick problem, and the first part of the question is provided in Figure 4 below:

Falling brick problem

While walking to school one day, you walked past a construction site. A crane was lifting a batch of bricks on a pallet, when suddenly a loose brick fell off the rising pallet. You estimated the time it took for the brick to hit the ground was 2.5 seconds.

a. What is the final velocity of the brick just before it hits the ground?

Figure 4: The falling brick problem (part a)

We crafted this question so that it was contextually rich and yet, in our opinion, simple enough for students to get the right answer, in order to motivate them. The solution to this question would be relatively simple: As the brick is falling, it undergoes constant acceleration that is provided for by gravity. Hence, using $v=u+a t$, we get:

$v=u+a t$ (where $v$ is final velocity; $u$ is initial velocity; $a$ is acceleration; $t$ is time)

$v=0+10 \mathrm{~ms}^{-2} * 2.5 \mathrm{~s}$ (taking $10 \mathrm{~ms}^{-2}$ to be the acceleration provided for by gravity)

$v=25 \mathrm{~ms}^{-1}$

However, to our bewilderment, more than three-quarters of the class had difficulties solving this question. We had initially thought that the students would take at most 5 minutes to solve this question, but on average, the students took over 30 minutes to solve this problem, and many were only able to solve it only after receiving help from either the teacher or the author. Provided below are protocol data snippets (continuous; no middle cropping was done) taken directly from the students' chat logs. Analysis of this protocol data indicates clearly that these students have a misconception about when the formula, velocity $=$ distance / time $(v=d / t)$, may be used. When appropriate, I have provided my own comments in square brackets ([...]) to aid the reader in understanding the context of the students' problem solving attempts. 


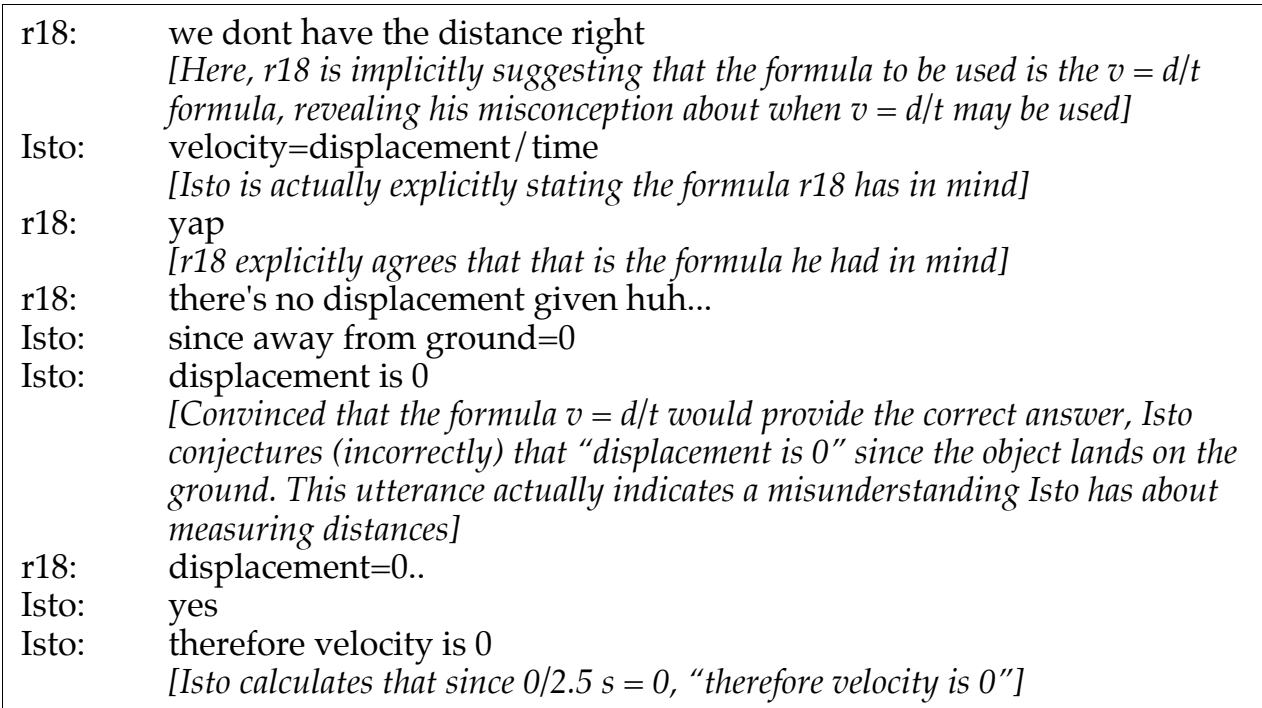

Protocol snippet 1: Speed, velocity, acceleration misconceptions

Bo: $\quad i$ think that the velocity when it is just above the ground is $0 \mathrm{~m} / \mathrm{s}$ [Bo makes a conjecture about the velocity of the brick]

Pavo: Why?

Bo: $\quad$ as it is just about to hit the ground,it slows down in velocity [Due to Pavo's probe, Bo explains his conjecture. This utterance indicates

quite clearly the naive conceptions Bo has with regards to falling objects]

Pavo: But ir does not totally stops, right?

[Unconvinced with Bo's explanation, Pavo suggests that the brick does not

Bo: the air resistance and weight are the same

[Here, Bo is suggesting that velocity is 0 because air resistance (the drag force) equals the weight force provided by gravity. This utterance reveals Bo's misconceptions about terminal velocity, where velocity actually remains constant and is not zero]

Pavo: Oh I see...

[We suspect that Pavo did not really fully understand Bo's explanation about "air resistance and weight". Rather, we believe Pavo was somewhat cowed by the "scientific explanation" offered by Bo and provided a response that would not cause him to appear as being ignorant]

Protocol snippet 2: Speed, velocity, acceleration misconceptions 


$\begin{array}{|ll|}\text { Kisko: } & \text { let's just focus on the problem } \\ \text { Sisu: } & \text { Q1? } \\ \text { Kisko: } & \text { yeap } \\ \text { Kisko: } & \text { q1 } \\ \text { Kisko: } & \text { part a } \\ \text { Sisu: } & \text { it only gave us one clue and it is the time } \\ & \text { [Here we see Sisu indicating that only time is given; notice that she does not } \\ & \text { take into account other information that is not explicitly provided] } \\ \text { Vee: } & \text { the time is } 2.5 \text { secs, so we have to use dist/time, right? } \\ & \text { [Vee builds on Sisu's comments, and states that the time given is 2.5s. Here, } \\ & \text { Vee suggests using the v }=d / t \text { formula, revealing her misconception about } \\ & \text { when that formula may be used] }\end{array}$

Protocol snippet 3: Speed, velocity, acceleration misconceptions

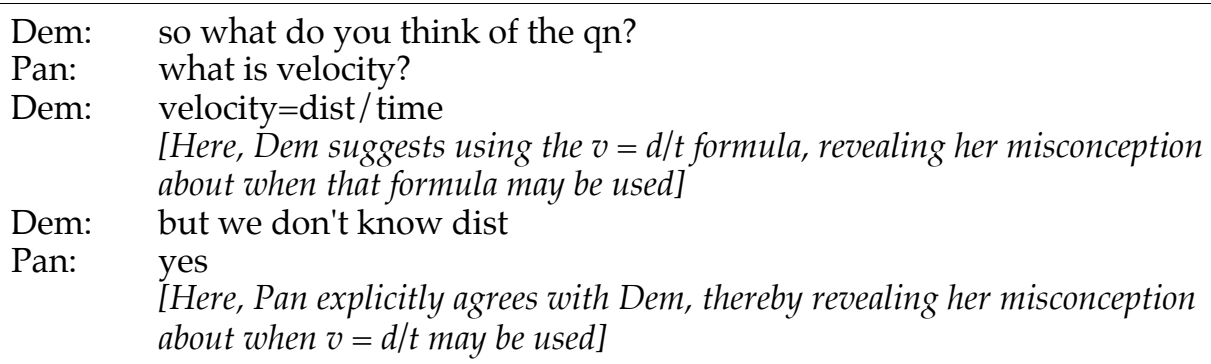

Protocol snippet 4: Speed, velocity, acceleration misconceptions

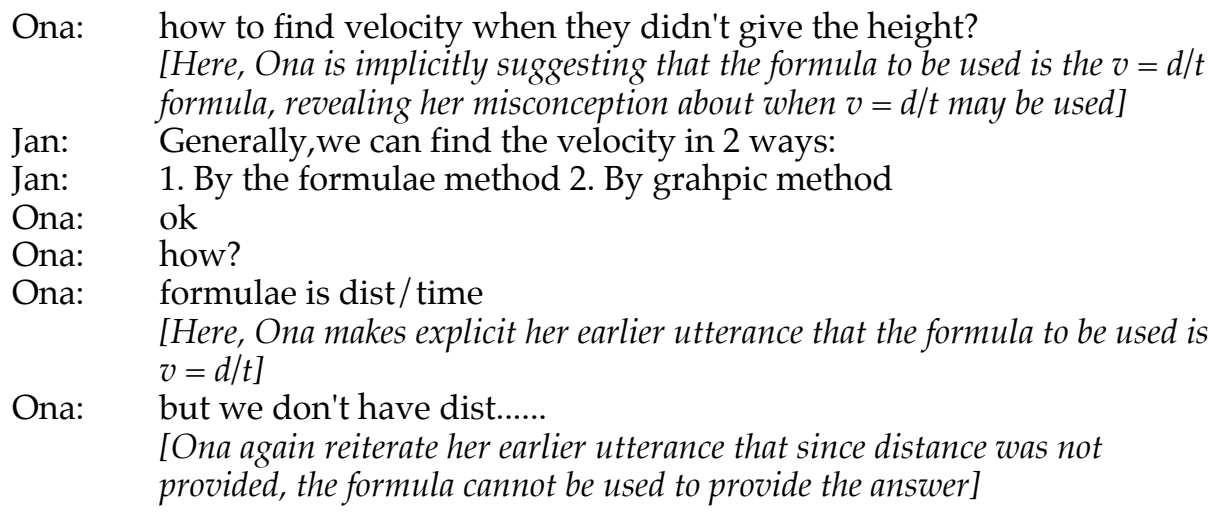

Ona: but we don't have dist......

[Ona again reiterate her earlier utterance that since distance was not provided, the formula cannot be used to provide the answer]

Protocol snippet 5: Speed, velocity, acceleration misconceptions 


$\begin{array}{ll}\text { r16: } & \text { i think the 1st q has no ans } \\ \text { Ida: } & \text { huh? } \\ \text { r16: } & \text { cause no height given } \\ & \text { [Here, r16 is implicitly suggesting that the formula to be used is the } v=d / t \\ & \text { formula, revealing his misconception about when } v=d / t \text { may be used] } \\ \text { Ida: } & \text { what does thw question mean? } \\ \text { Ida: } & \text { yeah i was thinking the same } \\ & \text { [Ida is explicitly agreeing with r16's last utterance, revealing her } \\ & \text { misconception about when the formula } v=d / t \text { formula may be used] }\end{array}$

Protocol snippet 6: Speed, velocity, acceleration misconceptions
Etu: $\quad$ velocity is dist / time
[Here, Etu states explicitly that $v=d / t$ formula, revealing her misconception about when that formula may be used]
Nea: $\quad$ i think so
[By agreeing with Etu, Nea reveals her misconception about when that formula may be used]

Protocol snippet 7: Speed, velocity, acceleration misconceptions

Rahe: displacement/time??

[Here, Rahe is suggesting that the formula to be used is the $v=d / t$ formula, revealing her misconception about when $v=d / t$ may be used]

Lumme: I don't think there is enough info.what do you think? [Lumme agrees with Rahe's suggestion, but points out that there is not enough information to use that formula]

Rahe: $\quad$ yes, like something missing [Rahe is implicitly implying that distance is missing]

Rahe: actually i forgotten how to do already

Lumme: Honestly ,I don't know the answer for the final velocity. [Rahe's and Lumme's utterances suggest that their problem-solving strategy essentially revolves around identifying the formula to be used and then applying it]

Protocol snippet 8: Speed, velocity, acceleration misconceptions

$$
\begin{aligned}
& \text { Hanko: } \begin{array}{l}
\text { okie start with qn } 1 \text { rite? wat the velocity } \\
\text { R20: }
\end{array} \\
& \begin{array}{l}
\text { So..... vel=displacement / time } \\
\text { [Here, R20 states explicitly that } v=d / t \text { formula, revealing her misconception } \\
\text { about when that formula may be used] }
\end{array} \\
& \text { Hanko: } \quad \text { yah } \\
& \text { [By agreeing with } R 20, \text { Hanko reveals her misconception about when that } \\
& \text { formula may be used] }
\end{aligned}
$$

Protocol snippet 9: Speed, velocity, acceleration misconceptions 


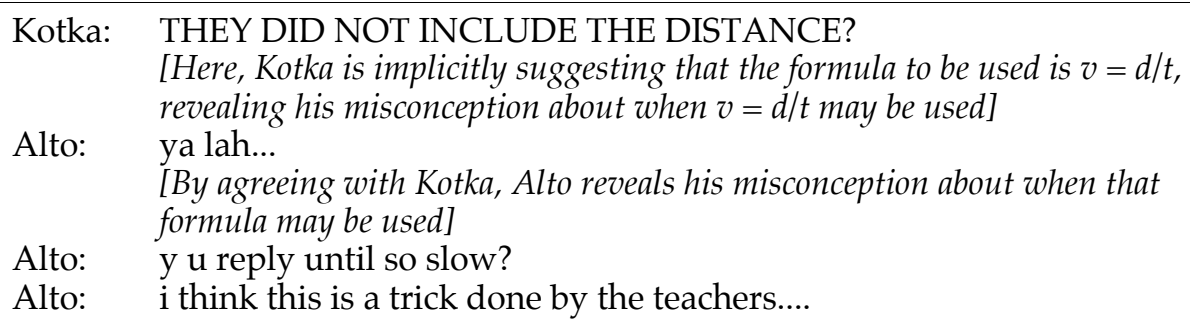

Protocol snippet 10: Speed, velocity, acceleration misconceptions

After the first computer mediated, collaborative problem solving session that day, the teacher and the author were corresponding via email, discussing the various misconceptions that the teacher had discovered while analysing the students' logs. In his email, the teacher wrote,

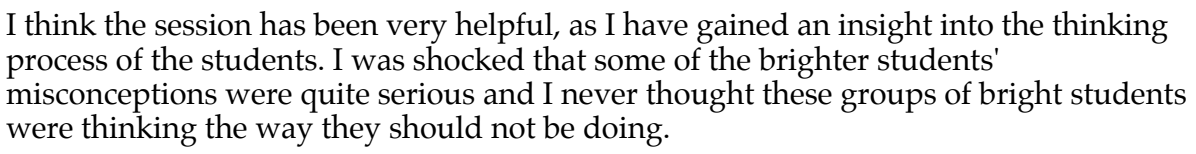

Discussions after subsequent CMC sessions were often characterised by surprise and a sense of amazement at the way the students were thinking, and the misconceptions that they had. In short, after four CMC sessions, we identified a total of 12 misconceptions that we identified as being "unexpected". This is a large number given the fact that these CMC sessions were considered revision sessions, as the entire syllabus had already been taught and the students were revising for their GCE "O" Level examinations, which were about four months away when we started the intervention.

\section{Discussion}

From a subject domain perspective, revision for physics (and also the other natural sciences) in schools is still typically done via the traditional method of "repetition and regurgitation" and "drill and practice" (for examples see Mortimer \& Scott, 2003; Cahyadi, 2007). For the most part, revision lessons involve teachers providing students with questions, such as those posed in previous examinations. Students, either individually or as a group, work on providing answers to these questions. The teachers evaluate the students' submissions, and based on the correctness of the answers provided by the students, decide how to revise a particular topic. It is possible for teachers to provide personalised attention and discuss various physics concept for an individual or small group of students. Based on the students' articulations during these personalised sessions, teachers could gain deeper insights into the students' thought processes as they are solving a problem or "thinking aloud" about a particular physics concept. However, it is difficult to provide such personalised instruction due to time constraints and as a result, the traditional mass approach to revision is still the norm.

A key weakness of the traditional revision methodology stems from the fact that teachers do not have access to students' thought processes in situ. This weakness is present because teachers are typically only able to peep into students' thought processes based on their explicit articulations (usually written or verbal). However, the 
traditional revision methodology - where students' articulations typically involve mainly providing teachers with the main steps (or worst still, only the final answer) of a proposed solution - does not provide teachers with deep enough insights into students' thought processes. Without deep insights into students' thought processes, teachers are unable to identify specific students' knowledge gaps. This deficiency may result in revision lessons not providing the necessary scaffolding students need in order to overcome their misconceptions or misunderstandings.

Results of this study suggest that if student pairs work collaboratively on solving physics questions via computer mediated communications software technology, the protocol data (i.e. text chat logs and computer whiteboard drawings) of their problem solving and knowledge co-construction attempts can provide teachers with rich insights into their thought processes as they are solving the physics questions posed. Hence, instead of marking submitted answer scripts and attempting to infer where a particular students' knowledge gap might be, the protocol data (as captured by the computer) would provide teachers with microgenetic data; data that is articulated by the students themselves. Upon analysing this data, teachers can then deliberately and specifically address individual students' knowledge gaps, based on their specific misconceptions or misunderstandings, as manifested in the protocol data. Such teaching practices are much more aligned with constructivist learning principles, and given the basic infrastructure required, this revision practice can potentially help teachers directly scaffold specific students' knowledge construction process. After all, teachers should orchestrate students' education (see Dewey, 1938; Westbrook, 1993), and by designing learning environments that help teachers know (much) more about how their students are thinking, teachers can help students learn better, thereby regaining (or maintaining, depending on which country you are looking at) the status that is rightfully theirs.

From a technology perspective, it has been observed by Salomon (2000) that, by and large, technology usage in education has become domesticated in the sense that technology is only allowed to do whatever the prevailing educational philosophy of learning allows it to do. As traditional pedagogical approaches and classroom practices have always supported the view that knowledge can be transmitted, the role of technology has been domesticated to assist in this transmission process. As Salomon noted,

Learners are to learn from the technology, but its uniqueness as tools of construction, communication and design to learn with, not from, is suppressed. Nobody wants to upset the prevailing practices by rocking the educational boat. (Salomon, 2000)

In our learning intervention, computers were used to mediate discourse between students to discover their current knowledge and understanding so as to scaffold knowledge construction. The results of our investigation strongly suggest that through the analysis of students' thought processes captured through computer mediated tools during collaborative problem solving, teachers (or facilitators) can obtain deeper insights into students' misconceptions and flawed reasoning. This outcome was achieved despite the fact that the technology (hardware and software) we used was commonly available (i.e. low end PCs running the Windows operating system with Intranet/internet access and NetMeeting installed). In our situation, it was the way the tool was used - rather than the technology itself - that influenced classroom practices. In contrast to using the computer as a medium for discourse, students could have used the computer as a source of "information" to learn from, such as by downloading class 
notes. Also, instead of using NetMeeting to facilitate students' collaborative work on problem solving, NetMeeting could alternatively be used to "teach" the students in a one to many fashion. Hence, technology itself is neutral and can be used either in a constructivist framework or otherwise.

While synchronous text chat and shared whiteboard technology (such as those provided by NetMeeting or other instant messaging software applications) may be considered "old technology" and more "modern" forms of technology use in schools may include blogs (e.g. Chong, 2008), wikis (e.g. Elgort et al., 2008), and games (e.g. Jamaludin et al., 2007), the technology that we used was entirely appropriate for our objectives. After all, we wanted students to collaboratively solve physics problems in an environment that allowed them to articulate their thought processes in a manner that would be made overt for our analysis so that subsequent classroom lessons would directly target students' misunderstandings. Hence, NetMeeting, although dated, was appropriate for this educational practice.

In sum, this study illustrates an alternative approach to the discovery of students' preconceptions and thought processes through the use of commonly available computer mediated tools. We believe that this approach could provide teachers with a practical trade off between depth of discovery of students' knowledge, and time, effort and resources needed. If the setting up of the CMC environment could be made simple, such as the execution of an automated script that would start the CMC tool and connect computers, we believe teachers could be more willing to try this approach.

\section{Further research}

I believe that the reasons for this [the popularity of reciprocal teaching] are (a) it looks deceptively easy to implement, (b) the term reciprocal teaching has been picked up by researchers, teachers, and textbook publishers and has become part of the discourse of the reading community, and (c) most important, the procedure slots neatly into a hallowed classroom niche. (Brown, 1992, p.172; see also Cuban, 1984)

In the quote above, Brown expressed her reasons for why the notion of reciprocal teaching has become widely disseminated. In a similar spirit, I believe there is a potential for computer mediated, collaborative problem solving to be widely used in schools because it could slot neatly into a hallowed "classroom niche" of in school revision for the natural sciences (e.g. physics, chemistry, biology). In order to assess this belief, further research should focus on evaluating (i) whether teachers, on their own, may be able to plan, organise and conduct the described CMC environment for student collaborative problem solving, (ii) whether teachers are able to make use of the protocol data in order to glean insights into students' preconceptions and thought processes, (iii) whether teachers are able to prescriptively address students' misconceptions and misunderstandings such that the students' results are improved significantly, and (iv) whether students enjoy learning in such an environment. After all, educational research is interested in bringing about improvements in educational practices (Moll \& Diaz, 1987; Pring, 2000), and no such improvements may be made without the participation and support of both teachers and students.

\section{Acknowledgements}

A presentation of the same title was presented at the University of Cambridge Faculty of Education annual internal conference (CamERA) on 16 April 2008. I am grateful to 
Professor Neil Mercer and Dr Sara Hennessy for their helpful comments on the contents that were covered during that presentation. Also, I am indebted to A/P Yam San Chee (NIE, Nanyang Technological University, Singapore) for the guidance he provided while I conducted the design experiment mentioned in this paper.

\section{References}

Aguirre, J. (1988). Student preconceptions about vector kinematics. The Physics Teacher, 26, 212216.

Arons, A. (1989). Guest comment: Proposed revisions of the introductory physics course. The American Journal of Physics, 57, 681-682.

Bowden, J., Dall'Alba, G., Martin, E., Laurillard, D., Marton, F., Masters, G., Ramsden, P., Stephanou, A. \& Walsh. E. (1992). Displacement, velocity and frames of reference: Phenomenographic studies of students' understanding and some implications for teaching and assessment. The American Journal of Physics, 60, 262-269.

Brown, A. (1992). Design experiments: Theoretical and methodological challenges in creating complex interventions in classroom settings. The Journal of the Learning Sciences, 2(2), 141-178.

Cahyadi, V. (2007). Improving teaching and learning in introductory physics. Unpublished doctoral dissertation, University of Canterbury, New Zealand.

Chen, W. \& Looi, C. K. (2007). Incorporating online discussion in face to face classroom learning: A new blended learning approach. Australasian Journal of Educational Technology, 23(3), 307326. http: / / www.ascilite.org.au/ajet/ajet23/chen.html

Chong, E. (2008). Harnessing distributed musical expertise through edublogging. Australasian Journal of Education Technology, 24(2), 181-194. http: / / www.ascilite.org.au/ajet/ajet24/ chong.html

Cuban, L. (1984). How teachers taught: Constancy and change in American education 1890-1980. NY: Longman.

Dallas (University of Dallas Department of Physics) (2008). Comprehensive conceptual curriculum for physics. http:/ / phys.udallas.edu/ [viewed 1 June 2008].

Dewey, J. (1916). Democracy and education. NY: Macmillan.

Dewey, J. (1938) Experience and education. New York: Macmillan.

Duffy, T. \& Cunningham, D. (1996). Constructivism: Implications for the design and delivery of instruction. In D. H. Jonassen (Ed.), Handbook of research for educational communications and technology. New York: Simon and Schuster, 170-198.

Elgort, I., Smith, A. \& Toland, J. (2008). Is wiki an effective platform for group course work? Australasian Journal of Educational Technology, 24(2), 195-210. http: / / www.ascilite.org.au/ajet/ajet24/elgort.html

Goldberg F. \& Anderson, J. (1989). Student difficulties with graphical representations of negative values of velocity. The Physics Teacher, 27, 254-260.

Heller, P. \& Heller, K. (1999). Cooperative group problem solving in physics. University of Minnesota Physics Education Research and Development. [viewed 19 Jan 2008]. http: / / groups.physics.umn.edu/physed/Research / CGPS/GreenBook.html

Hsi, S. (1997). Facilitating knowledge integration in science through electronic discussion: The multimedia forum kiosk. Unpublished Doctoral Dissertation, University of California at Berkeley.

Hung, D. (1996). The social construction of mathematical meanings through computer-mediated collaborative problem solving environments. Unpublished Doctoral Dissertation, National University of Singapore. 
Hung, D. (1998). Epistemological change through peer apprenticeship learning: From rule-based to idea-based social constructivism. International Journal of Computers for Mathematics Learning, $3(1), 45-80$.

Jamaludin, A., Ho, C., \& Chee, Y. (2007). Argument-based negotiation and conflict resolution through enactive role play in Second Life. Proceedings of the 15th International Conference on Computers in Education. Hiroshima, Amsterdam: IOS Press. 561-568.

Jehng, J (1999). Exploring learning potentials in network-enhanced learning environment. Proceedings of ED-MEDIA. Charlottesville, VA: ACCE. 675-680.

Kang, S., Scharmann, L., Noh, T. \& Koh, H. (2005). The influence of students' cognitive and motivational variables in respect of cognitive conflict and conceptual change. International Journal of Science Education, 27(9), 1037-1058.

Lantolf, J. (2000). Introducing sociocultural theory. In J. P. Lantolf (Ed.), Sociocultural theory and second language learning. Oxford: Oxford University Press, 1-28.

Lockyer L., Harper B. \& Patterson J. (1999), Health education in a web-based learning environment: Learners' perceptions. Proceedings of ED-MEDIA. Charlottesville, VA: ACCE. 56-61.

Lund, K. \& Baker, M. (1999). Teachers' collaborative interpretations of students' computermediated collaborative problem solving interactions. Proceedings of Artificial Intelligence in Education. Amsterdam: IOS Press. 147-152.

McDermott, L., M.L. Rosenquist, M. \& van Zee, E. (1987) Student difficulties in connecting graphs and physics: Examples from kinematics. The American Journal of Physics, 55, 503-513.

Mercer, N. (1995). The guided construction of knowledge: Talk amongst teachers and learners. Clevedon: Multilingual Matters.

Merzbacher, E. (1990). Guest comment: How shall we teach physics in the 21st century? The American Journal of Physics, 58, 717-718.

Moll, L. C., \& Diaz, S. (1987). Change as the goal of educational research. Anthropology $\mathcal{E}$ Education Quarterly, 18(4), 300-311.

Montana (Department of Physics at Montana State University) (2008). Student Difficulties in Physics Information Center. http: / / www.physics.montana.edu/physed/misconceptions / [viewed 1 June 2008].

Mortimer, E. \& Scott, P. (2003). Meaning making in secondary science classrooms. Buckingham, UK: Open University Press.

Nersessian, N. (1998). Conceptual change. In W. Bechtel, \& G. Graham (Eds), A companion to cognitive science. Oxford, UK: Blackwell Publishers, 157-166.

$\mathrm{Ng}$, C. S. L. \& Cheung, W. S. (2007). Comparing face to face, tutor led discussion and online discussion in the classroom. Australasian Journal of Educational Technology, 23(4), 455-469. http: / / www.ascilite.org.au/ajet/ajet23/ng.html

Ogborn, J. (2004). Physics education. In J. Ogborn (Ed.), Physics now: reviews by leading physicists in the International Union of Pure and Applied Physics. International Commission on Physics Education, 81-87.

Olenick, R. (2005). Stop I can't fit anything more into my head: How students learn physics. Address at NSTA (National Science Teachers Association) National Conference, Dallas: http: / / phys.udallas.edu/physics / rpo/ NSTA\%20April\%201,\%202005\%20Talk.pdf [viewed 1 May 2008].

Piaget, J. (1972). Science of education and the psychology of the child. NY: The Viking Press.

Price, B. \& Petre, M. (1997). Large-scale interactive teaching via the Internet: Experience with problem sessions and practical work in university courses. Proceedings of ED-MEDIA. Charlottesville, VA: ACCE. 1041-1050. 
Pring, R. (2000). The focus of educational research - educational practice and policy. In G. Thomas \& R. Pring (Eds), Philosophy of educational research. London: Continuum, 8-30.

Resnick, L. (1989). Introduction. In L. Resnick (Ed.), Knowing, learning and instruction: Essays in honor of Robert Glaser. Hillsdale, NJ: Lawrence Erlbaum Associates, 1-24.

Roschelle, J. (1995). Learning in interactive environments: Prior knowledge and new experience. http:/ / www.exploratorium.edu/IFI/ resources / museumeducation/priorknowledge.html [viewed on 1 May 2008]

Rorty, R. (1991). Objectivity, relativism, and truth. Cambridge: Cambridge University Press.

Salomon, G. (1998). Novel constructivist learning environments and novel technologies: Some issues to be concerned with. Research Dialogue, 1(1), 1-12.

Salomon, G. (2000). It's not just the tool, but the educational rationale that counts, Keynote address at Ed-Media 2000, Montreal. [viewed 15 Oct 2007, verified 3 Nov 2008] http:/ / www.aace.org/ conf/edmedia/00/salomonkeynote.htm

Schwartz, B. (1990). Guest comment: Improving the teaching of physics. The American Journal of Physics, 58, 1031-1032.

Shuell, T. (1986). Cognitive conceptions of learning. Review of Educational Research, 56, 411-436.

Shuell, T. (1990). Teaching and learning as problem solving. Theory into Practice, 29(2), 102-108.

Soong, B. \& Chee, Y. (2000). Scientific revolutions and conceptual change: Results of a microgenetic process study. ICCE/ICCAI Eighth International Conference on Computers in Education/International Conference on Computer-Assisted Instruction, Taipei, 165-172.

Strike, K. \& Posner, G. (1985). A conceptual change view of learning and understanding. In L. H. T. West \& A. L. Pines (Eds.), Cognitive structure and conceptual change. NY: Academic Press, 211-231.

Trowbridge, D. \& McDermott, L. (1980). Investigation of student understanding of the concept of velocity in one dimension. The American Journal of Physics, 48, 1020-1028.

Trowbridge, D. \& McDermott, L. (1981). Investigation of student understanding of the concept of acceleration in one dimension. The American Journal of Physics, 49, 242-253.

Voska, K. \& Heikkinen, H. (2000). Identification and analysis of student conceptions used to solve chemical equilibrium problems. Journal of Research in Science Teaching, 37(2), 160-176.

Vygotsky, L. (1978). Mind in society: The development of higher psychological processes. M. Cole, V. John-Steiner, S. Scribner \& E. Souberman (Eds. and Trans.). Cambridge, MA: Harvard University Press.

Westbrook, R. B. (1993). John Dewey. Prospects: The quarterly review of comparative education, 23(12), 277-291.

Benson Soong, Faculty of Education, University of Cambridge

184 Hills Road, Cambridge CB2 2PQ, United Kingdom. Email: bmhs2@cam.ac.uk 